\title{
Report on the First Neurological Disorders Summit (NDS-2015)
}

\section{Jin Jun Luo}

Departments of Neurology and Pharmacology, Temple University School of Medicine, Philadelphia, Pennsylvania, USA

\author{
Correspondence to: \\ Jin Jun Luo, MD, PhD \\ Departments of Neurology and Pharmacology \\ Temple University School of Medicine \\ Philadelphia, Pennsylvania, USA \\ E-mail: jluo@temple.edu
}

Received: September 3, 2015

Accepted: September 9, 2015

Published: September 11, 2015

Citation: Luo JJ. 2015. Report on the First Neurological Disorders Summit (NDS-2015). JNeurol Exp Neurosci 1(1): 20-21.

Copyright: (C) 2015 Luo. This is an Open Access article distributed under the terms of the Creative Commons Attribution 4.0 International License (CC-BY) (http://creativecommons.org/licenses/ by/4.0/) which permits commercial use, including reproduction, adaptation, and distribution of the article provided the original author and source are credited.

Published by United Scientific Group

\section{Meeting Report}

Neurological Disorders Summit (NDS-2015) concluded successfully on July 08,2015 . The three day summit was organized by United Scientific Group during July 06-08, 2015 at DoubleTree By Hilton, San Francisco, USA. The event was attended by speakers and delegates from more than 25 countries of the globe. The theme of NDS-2015 was Improvising Advanced Tools and Techniques for Better Therapeutics. The summit witnessed 8 keynote presentations, around 80 oral presentations and 30 poster presentations on various topics including Alzheimer's disease, Parkinson's disease, biomarkers, autism, stroke and other neurological disorders.

Dr. Kenneth Blum from University of Florida talked about biologically based genomic therapy for brain reward deficiency syndrome during his keynote lecture on Day 1. Dr. Blum discussed about the scope and challenges of incorporating gene therapy in treatment of various addictions. The Neuroimaging veteran Dr. ZangHee Cho from Korea illustrated about the recent progresses on neuroimaging with Ultra-high Field MR; he discussed about the brain dedicated PET-MRI. The possibility of innovative non-invasive intranasal method of bypassing the blood-brain barrier (BBB) to deliver and target therapeutics to the CNS was presented by Dr. William H. Frey II in his 30 minutes keynote lecture. Dr. Shoji Tsuji from Japan was also one of the keynote and talked about genomics view of neurodegenerative diseases. The Day 1 was highlighted with the talk of some of the highly eloquent speakers and well know scientists working on Parkinson's disease and Alzheimer's disease. The list includes Dr. Anthony J. Hannan from Australia, Dr. Joel N. Buxbaum from Scripps Research Institute, Dr. Wagner Zago from Prothena Biosciences, Dr. Joy L. Taylor, Dr. Martine Simard and Dr. Joy L. Taylor.

Day 2 started with the keynote of Dr. Ahmad Salehi on beta adrenergic signaling in Down syndrome and Alzheimer's disease; the presentation emphasized on the atrophy and dysfunction of hippocampal region with significant role in cognitive function in mouse model. Dr. Salehi also indicated that L-DOPS (an NE pro-drug) and formoterol (a long-acting beta2 adrenergic receptor agonist), can significantly improve contextual learning in the Ts65Dn mouse model of DS. Dr. Salehi's keynote was followed by the keynote of Dr. Giulio Maria Pasinetti, Dr. Rajendra D Badgaiyan and Dr. Afaf El-Ansary. Posters were presented in the poster session after the keynote. Many young researchers from Japan, Korea, China, USA and India presented their novel work. After a series of interesting talks on Autism, Biomarkers and other Neurodegenerative diseases Day 2 ended with a great socializing reception in the evening.

The last day of the summit was mainly focused on Stroke and Multiple sclerosis. Dr. Francisco S. Cayabyab, Dr. Hua Su, Dr. Ye Wang, Dr. Anat Biegon and Dr. Rina Aharoni were some of the key speakers on Day 3. NDS-2015 ended 
with the awards and certificates distribution to the speakers and presenters.

The proceeding of the conference will be published in the Journal of Neurology and Experimental Neuroscience launched during NDS-2015 by founding Editor-in-Chief Dr. Jin
Jun Luo. The summit also provided platform to launch the first journal dedicated to the concept of Reward Deficiency Syndrome (RDS) featured as Journal of Reward Deficiency Syndrome by Dr. Kenneth Blum.

\section{Submit Your Next Manuscript}

We are currently accepting submissions from new authors. Read our inaugural issue articles and submit your next manuscript to Journal of Neurology and Experimental Neuroscience (JNEN).

Submit Online: http://www.editorialmanager.com/usg 